\title{
Evaluation of Seasonal Characteristics of Land Surface Temperature with NDVI and Population Density
}

\author{
Javed Mallick* \\ Department of Civil Engineering, College of Engineering, King Khalid University, \\ P.O. Box: 394 Abha 61411, Kingdom of Saudi Arabia
}

Received: 14 October 2020

Accepted: 19 November 2020

\begin{abstract}
Vegetation cover and population density and its variability characteristics in National Capital Region, NCR, India have major effects on thermal environments, mainly on land surface temperature (LST). There are very few meteorological stations to record the surface temperature in earlier periods, and they may not be the true representation for NCR region. In such cases, LST derived from thermal satellite data is useful to study the LST variability across the NCR region, an important parameter for urban micro-climate. Satellite images from Moderate Resolution Imaging Spectroradiometer (MODIS) used to obtain Normalized Difference Vegetation Index (NDVI) and LST map to determine the impact of those parameters on LST variability. Higher NDVI reveals the lower LST and vice versa. The high LST-NDVI negative correlation was observed during monsoon season. Statistical analysis of nighttime LST with population density shows that population growth tends to lead to urban LST rise or Urban Heat Island (UHI) strength, as well as effects NCR micro-climate. The high population density is one of the key contributing factors for NCR's high surface temperature, UHI intensity and also micro-climate. The study shows that the seasonal distribution of LST needs to be overcome with the high vegetation cover and some other appropriate mitigation measures. One way of mitigating such seasonal peripheral thermal effects could be to adopt better cropping practices in order to minimize the agricultural fallow period and promoting green roofing concepts in urban areas and using porous concrete for construction which might help to mitigate impacts of high LST in urban areas of NCR. The results of these studies may be useful in assessing and resolving the microclimate problem and in reducing the impact of UHI and also provide supporting data for NCR's urban planning and environmental research.
\end{abstract}

Keywords: Thermal Environment, LULC, Seasonal Variation, Urban Heat Islands, MODIS

*e-mail: jmallick@kku.edu.sa 


\section{Introduction}

Urban environmental studies are becoming an important research area in today's globalization and industrialization world. Land surface temperature (LST) is an important parameter in urban climate $[1,2]$. Satellite data is used to determine thermal characteristics of urban land surfaces by mapping and evaluating surface temperatures from thermal infrared images [3-5]. In urban development (population pressure), removing and replacing natural land-cover class with common urban materials viz. asphalt, concrete, stone, brick and metal has major environmental effects, such as reduced evapotranspiration, facilitating faster runoff, heat transfer and storage problems and deterioration of air and water quality. The effect of transition may have significant impacts on micro-climate and local environment [6]. Significant variability in urban temperature is explained as a framework of population growth [7]. The above-mentioned comprehensive impacts of land use, water and vegetation have climatic and meteorological effects on the urban environment on different scales, and these indicators are linked to population growth. With rising urban size and/ or growth, the severity of micro-climate change (as increases in urban heat island (UHI) rates) continues to increase, and as cities grow, they are gradually contributing to climate change beyond the local level [6].

Natural and agricultural landscapes are increasingly transformed into urban and suburban occupations than urban population growth in the core urban areas. Cities do not grow in an isodiametric way; on the contrary, they spread in spider-like systems along the radial routes that encompass the satellite hamlets and also spread to their natural lands. This anthropogenic pattern and process has led to changes in the environment, hydrology, soil, species composition and population patterns, and these urban environments are very different from natural ecosystems.

Over the last several decades, the enormous rate and scale of urbanization of the NCR has placed considerable stress on the city's natural resources and confronted its adverse effects [8]. Over the past 50 years, the rate of environmental degradation has risen much higher than the rate of urbanization. This includes loss of green cover, loss of biodiversity and aesthetics; increased air, surface and groundwater pollution; loss of water bodies, depletion of water table, high disease and mortality.

For the study of ecological dynamism of the NCR sub-region, the complexity of the sprawling urban landscape and its environmental effects in the NCR, urban landscape ecology was considered a wise viewpoint. Landscape ecology in urban areas may be the first attempt to investigate how human action by converting spatial patterns can affect surface flows in urban environments, such as thermal conditions. The patterns of spatial structure and land use directly affect the flow of urban energy through redistribution of solar radiation. In addition, the level of greenhouse gasses (GHGs) in the urban environment is not only controlled by the location of land, pollutant sources, but also by the trend of artificial micro-zone heat generation. In addition, land use patterns directly and indirectly affect local sinks with water bodies and green areas that mitigate the impact of the urban thermal environment and absorb pollution.

With rising concretization and related changes in land use/land cover (LU/LC) in urban areas, patterns of surface temperature have transformed that evolve divergent micro-climates in towns and cities $[9,10]$. Industries, motor vehicles, air conditioning and other activities in the urban lifestyle add extra heat to nearby areas [11]. As a result, high-temperature islands are being formed in some parts of urban areas called urban heat island (UHI), while relatively cool suburbs are being felt. Worldwide, there is exponential urban growth, about $30 \%$ of the world 's population lives in urban areas in 1950, and $66 \%$ of the population is projected to live in urban areas by 2050. According to India's 2011 census, 833 million (68.84\%) of 1.21 billion Indians live in rural areas, while 377 million $(31.16 \%)$ live in urban areas. In India, urbanization rose from $27.81 \%$ in 2001 to $31.16 \%$ in 2011 . Moreover, 42.6 percent of urban population live in India's 53 metropolitan cities. India's four largest cities i.e. Mumbai, Kolkata, Delhi and Chennai together make up $15.4 \%$ of India's urban population. In NCR (sub-region Haryana, UP, Rajasthan and NCT-Delhi) about $7.6 \%$ and $2.11 \%$ of urban and rural population, respectively, of the total Indian population. Approximately $4.4 \%$ of India's urban population lives in Delhi alone. NCR's urban population rose from $50.2 \%$ in 1991 to $62.5 \%$ in 2011, while NCR's rural population declined by share percentage from $49.8 \%$ in 1991 to $37.5 \%$ in 2011 .

Urban population data show incresting trends in urban popultaion. Therefore, to accommodate these people in urban settings, the community needs more buildings and other related activities from instructional, commercial and recreational purposes etc. This leads to an increase in the area under construction and, as a result, the LST is assured of an increase which is an indicator of the thermal environment in urban areas. The LST of an urban area is affected by many factors such as season, daytime, terrain, precipitation, wind, local climate, geographic area, landscape, materials and morphology [11,12]. The LST has an implied but significant impact on air temperatures, especially the closest canopy layer to the surface [3]. The vegetated areas act as the lungs of the city and help to control low temperatures [13].

The LST also varies over different LU/LC with the changing seasons $[14,15]$. The magnitude of the surface temperature varies with seasons due to changes in sun intensity, landscape features and atmospheric conditions. The earth's surface temperature is usually higher in summer than in winter due to this variability. 
Several studies have been conducted on the seasonal analysis of urban thermal environments e.g. Pandey et al. [16] tested UHI in summer for day and night conditions in Delhi. Li et al . [17] examined Shanghai's seasonal UHI shifts. Mallick et al. [18] evaluated the temporal and spatial variations in LST strongly associated with impervious surface area to study the effects of urbanization on NCT-Delhi spring season. Weng and Yang [19] investigated the potentially negative thermal effects of urban growth during summer and winter seasons in Guangzhou, China. But there is a lack of studies in India to understand seasonal variation of environmental conditions, particularly regional thermal environmnet.

LST and NDVI are crucial to understanding the dynamics between ecosystem processes and the changing seasons in an environmentally sensitive area. Study on the correlation with LST and NDVI [20] illustrates the factors that trigger environmental degradation, major changes in the land-based environment's carbon cycle, and demonstrates the factors that regulate land's response to climate variability" [21]. Throughout the past two decades, multiple studies have attempted to establish the relationship between NDVI and LST in different regions and ecosystems [8, 22-25]. Nevertheless, vegetation response mechanisms are still unclear [26]. Many of these studies refer directly to NDVI and LST as variables or investigated their spatial variability mostly during growing season [27]. Nevertheless, there have been no NCR region studies based NDVI with LST on different seasons. Therefore, studying vegetation changes and the relationship between NDVI and LST in NCR region is essential.

Oke [28] developed a regression model for North American and European cities that demonstrated that $97 \%$ of UHI intensity variation is because of a single predictor variable-population size. A population-based study related to changes in urban temperature (USA) identified a local rise of about $1^{\circ} \mathrm{C}$ per 0.1 million people due to urbanization [29]. Analyzed the effects of urbanization on climate change using urban and rural population and meteorological data [29] and LST measurements using data from night-light satellite [30]. The climate is affected by changes in LU/LC and anthropogenic factors in and around cities and other built-up areas [28, 31, 32].

With this background of the real issue and the lack of research into interseasonal variations in the thermal environment, in particular in NCR, India, this study is of utmost importance as it relies on understanding the temporal relationship between land surface temperature mechanics for LU \LC and vegetation cover (NDVI)" in the National Capital Region (NCR) over the five seasons. Second, analyze the relationship between NDVI with population density and LST with population density. To assess and resolve the micro-climate problem and also to mitigate the effect of thermal environment on the NCR population.

\section{Study Area}

Geographically the NCR extends between $26^{\circ} 43^{\prime} 17.118^{\prime \prime}$ to $29^{\circ} 27^{\prime} 35.353^{\prime \prime}$ North latitude and $78^{\circ} 28^{\prime} 13.306^{\prime \prime}$ to $75^{\circ} 28^{\prime} 52.402^{\prime \prime} \mathrm{E}$ longitude and the altitude varies between 155 and 755 meters, with the mean of 240 meters, it covers an area of 46,208 $\mathrm{km}^{2}$ (as per 2013 amendment and area of study of this research) and is situated in the northern part of India. NCR's physiography is distinguished by the presence of the Ganges river on the eastern border, the Yamuna river from north to south creating the boundary between the states of Haryana and UP, and the dunes and barren low hills of Mount Aravali and its rocky outcrops situated west. The rolling plains were dominated by rain-fed streams in the, whereas south-west, the rugged flat-topped \& "precipitous hills of the Aravalli range enclose the fertile valley and high plateaus". The rest of the NCR is plain and gentle slopes from northeast to south and southwest. India has a population of 1210 million according to the 2011 Census, with an urban population of 377 million. Urbanization in India rose from $27.81 \%$ in 2001 to $31.20 \%$ in 2011 . In NCR (sub-region Haryana, UP, Rajasthan and NCT-Delhi) comprises about $7.6 \%$ and $2.11 \%$ of urban population and rural population of total India's population respectively. Approximately $4.4 \%$ of the urban population of India lives in NCT Delhi alone. In 2011, the NCT-Delhi accounted for the largest proportion of population (36.4\%), after that UP sub-region (31.6\%) and Haryana sub-region (24.0\%). The Rajasthan subregion represents the lowest rate of $8.0 \%$. The total population of NCR in 2011, had 46.05 million. Since 1981, the percentage of the population (ratio) in the subregions of Rajasthan and Haryana has been fairly stable; however, NCT-Delhi has increased from $31.4 \%$ in 1981 to $36.4 \%$ in 2011 , "while in U.P sub-region it reduces from $35 \%$ to $31.6 \%$ during the same period.

\section{Data and Method Used}

Descriptions of data sets from various sources used in this study are given as, (a) MODIS NDVI, spatial resolution of $250 \mathrm{~m}, 16$-day composite raster data L3 product (MOD13Q1) was obtained from NASA Earth Observation System (EOS) data gateway for January 2011 to December 2011 and January 2017 to December 2017, (b) MODIS LST level-3 data (MOD11A2 L3) with $1000 \mathrm{~m}$ spatial resolution available in every eight days were downloaded from the NASA Earth Observation System (EOS) data gateway from for January 2011 to December 2011 (night-time) and January 2017 to December 2017, (c) Field visit and Google Earth data were used in the study area to analyze, validate and monitor land use.

The descriptions of the methodological approach for evaluating the different data sets are addressed below. 


\section{Base Layers Creation}

Base maps such as the sub-regions of the NCR, India, district boundaries, roads, water bodies etc. were created from SOI toposheet at a scale of 1:50000. In this study, NCR region divide up the year into five seasons: winter, spring, summer, monsoon, and autumn. Each season lasts 2-3 months with summer being the warmest season, winter being the coldest, monsoon being the rainy, and spring and autumn lying in between of winter and summer. Winter season (Dec. and January), spring season (Feb. and March), summer season (April, May, June), monsoon season (July, Aug. and Sept.) and autumn season (Oct. and Nov.)

\section{Georeferencing of MODIS NDVI Data}

MODIS NDVI data have been projected onto UTM WGS84 and resampled to a $250 \mathrm{~m}$, followed by layer stacking and region of interest (ROI) subsetting.

\section{Georeferencing of MODIS LST Data}

MODIS LST data were projected to UTM WGS84, followed by clipping the study area. These $1000 \mathrm{~m}$ MODIS data were resampled to a $250 \mathrm{~m}$ grid using the nearest neighborhood technique, in compliance with the MODIS NDVI bands. There is a scale factor of 0.0001 or $1 / 10000$. It demonstrates that to achieve the real data value a value of 10,000 in the raster will be multiplied by 0.0001 .

\section{LST Computing Using MODIS LST Bands}

MODIS Land Temperature/Land Surface Emissivity (LST/LSE) data were multiplied by a 0.02 or $2 / 100$ scale factor. This implies multiplying an LST value in the raster by 0.02 to obtain the real data value.

\section{Seasonal NDVI Estimation}

Daily images were consisted semi-monthly (two per month, on the first day of the month to the fifteenth and from the sixteenth to the end of each month) using the maximum recorded value NDVI. Rather than the mean semi-monthly periods, maximum NDVI values have been used to ensure that any residual cloud coverage would have the minimal effect on our results.

\section{LULC Map}

The LULC map was produced using LANDSAT- 8 and resampled to a $250 \mathrm{~m}$ using the nearest neighborhood technique, in accordance with MODIS NDVI bands. The six LULC categories were based on the 1996 NRSC classification scheme for agricultural, built-up, water bodies, scrubland, bare soil/exposed rocks and vegetation. In April to May 2017 (cloud-free date), comprehensive field survey was conducted to collect land cover information. Sample locations were recorded using a handheld global positioning system (GPS) with accuracy below $5 \mathrm{~m}$.

\section{A Seasonal Pattern/Trend Analysis}

The statistics of surface temperature and NDVI by LU/LC types were obtained by overlaying LU/LC map with LST, and NDVI. In order to evaluate their distribution in different seasons (autumn, summer, monsoon, spring and winter), NDVI and LST data were analyzed.

\section{Statistical Analysis}

Statistical analysis is performed to evaluate the seasonal relationship between NDVI, LST and LULC data.

\section{Population Density}

Population density data of 2011 calculated from Census of India and population density of tahsil wise (sub-districts-wise) data was analyzed using GIS platform.

\section{Results}

\section{Season-wise Analysis of Relationship between Day Time LST and NDVI}

Literature has widely documented LST-NDVI relationship [3, 5, 33]. The "correlation coefficients" of each LULC type were determined from NDVI and LST using MS Excel and SPSS statistical tools. Five seasons of NDVI and LST for 2017 (winter, spring, summer, monsoon and autumn) were under evaluation for this study. In this section, an attempt was made to draw seasonal relationships between LST knowledge and NDVI to evaluate this relationship, the selected surface temperatures and NDVI values were obtained in the same year using the statistical tool from ENVI with ROI masks of covering all type of land use/land cover class. Random sampling was used for the analysis of LST and NDVI. The pixels (covering all the feature classes) were selected for linear regression analysis, as the spatial resolution of "MODIS data" is low and therefore it is difficult to select representative pure pixels, the classes selected for different classes based on $<40 \%$ recognize pure pixels. Fig. 1 shows scatter plot between the LSTNDVI for all five seasons.

It is noticed that monsoon season reveals higher relationship between LST-NDVI. During Monsoon season, the NDVI value ranges from 0.009 to 0.899 with an average of 0.575 and LST value ranges $19.41^{\circ} \mathrm{C}$ to $42.08^{\circ} \mathrm{C}$ with a mean value of $33.35^{\circ} \mathrm{C}$. It is seen that LST has negative $(-0.55)$ correlation with NDVI. 
Table 1. Season-wise correlation between LST and NDVI (2017).

\begin{tabular}{|c|c|c|c|}
\hline Seasons & & LST & NDVI \\
\hline \multirow{3}{*}{ Winter Seasons } & LST & 1.000 & $-0.0007^{*}$ \\
\cline { 2 - 4 } & NDVI & $-0.0007^{*}$ & 1.000 \\
\hline \multirow{3}{*}{ Spring Seasons } & LST & 1.000 & $+0.0387^{*}$ \\
\cline { 2 - 4 } & NDVI & $+0.0387^{*}$ & 1.000 \\
\hline \multirow{3}{*}{ Monsoon Seasons } & LST & 1.000 & $-0.5503^{*}$ \\
\cline { 2 - 4 } & NDVI & $-0.5503^{*}$ & 1.000 \\
\hline \multirow{3}{*}{ Summer Seasons } & LST & 1.000 & $-0.4037^{*}$ \\
\cline { 2 - 4 } & NDVI & $-0.4037^{*}$ & 1.000 \\
\hline \multirow{3}{*}{ Autumn Seasons } & LST & 1.000 & $-0.3988^{*}$ \\
\cline { 2 - 4 } & NDVI & $-0.3988^{*}$ & 1.000 \\
\hline
\end{tabular}

* Correlation is significant at 0.05 level of significance (1-tailed)

In Monsoon season, the strength of the correlation is higher than in other four seasons. Due to heavy rainfall, growth of vegetation increases during monsoon season, and therefore NDVI values are high. Table 1 shows the LST-NDVI correlation for NCR (pixel by pixel). There are few exceptions to the negative association between LST and NDVI (vegetation density). This means where NDVI is high, the land surface temperature is low and vice versa.

\section{Season-wise Relationship between NDVI and Population Density in NCR}

The vegetation cover is considered a key indicator of land status. The Normalized Differenced vegetation index is the most commonly used index of vegetation. The NDVI is calculated based on the remotely sensed reflection over their sum of visible (red) and near-infrared vegetation surfaces and provides information on photosynthetically active vegetation's density, condition and health [34]. A divergence from the standard indicates either land degradation or improvement, accounting for climate, land use, terrain, soils, and NDVI has increasingly been used to evaluate a variety of ecosystem services.

Urban area observation (e.g. spatial distribution development) may provide the ability to identify false alarms within NDVI maps that occur as a result of land use and change. It is possible to identify and take action to mitigate agricultural land or land generally transferred to urban areas. The NCR-Map of urban areas, extracted from MODIS data, defines urban areas as places populated by built environments, including non-vegetated and human-built elements, as all humanmade constructions. Socio-economic data [35] has been developed on the GIS platform, which provides information on rural and urban areas as well as on the spatial distribution of human populations within a common geo-referenced satellite-based framework.

In the present study, the five classes of population density used to analyze the population's role as
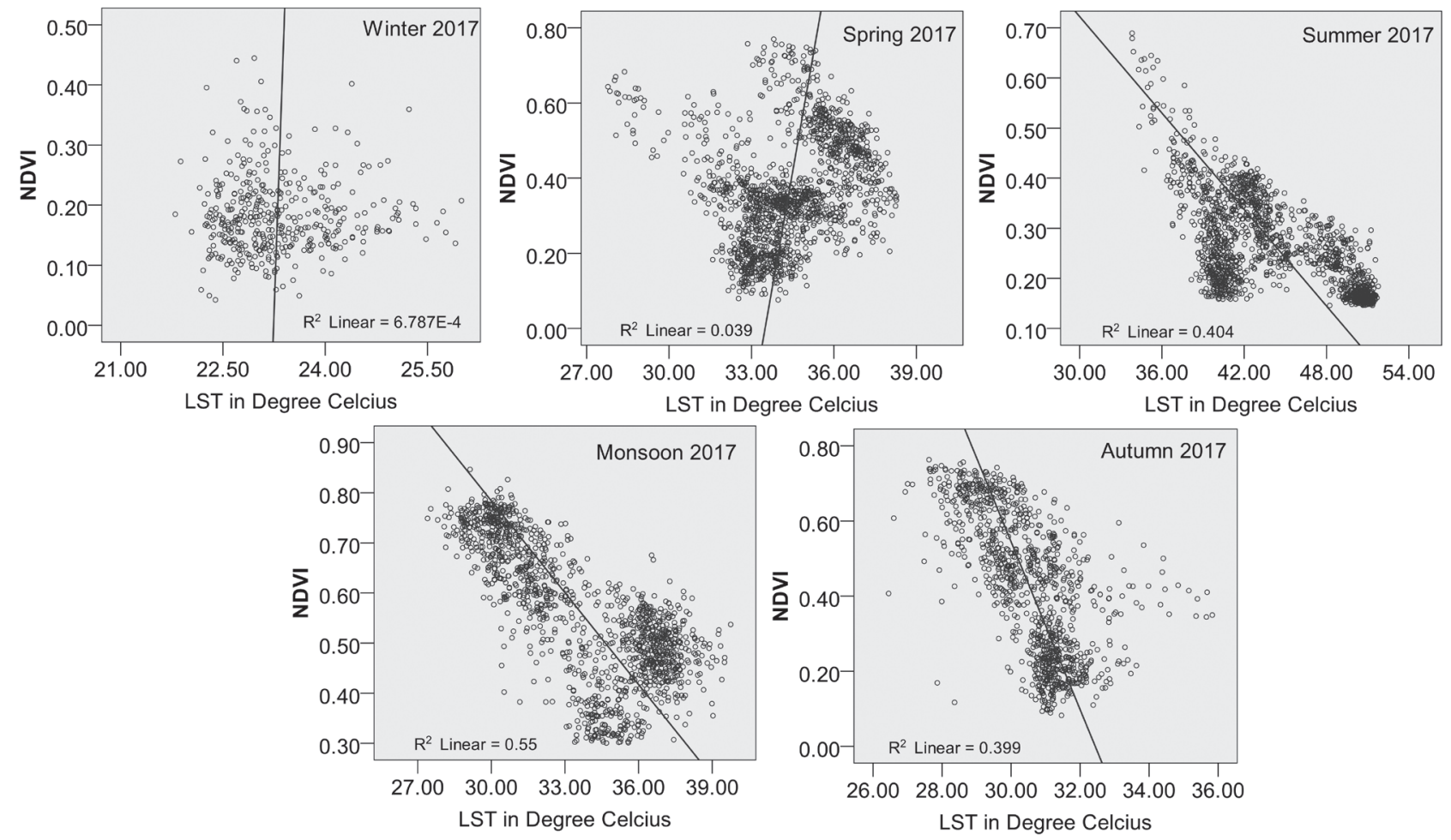

Fig. 1. Scatter plot between the LST-NDVI for all five seasons during 2017. 
a factor in land degradation (via NDVI): very low, low, medium, high, and very high. The NDVI value derived from MODIS NDVI 16-day composite grid data L3 product with $250 \mathrm{~m}$ spatial resolution. Daily images were composed in semi-monthly periods (two per month, from the first day of the month to the fifteenth and from the sixteenth to the end of the month) using the maximum NDVI recorded. Instead of the average semi-monthly periods, maximum NDVI values were used to ensure the minimum effect on our data of any remaining cloud coverage. Whereas seasonal NDVI was obtained using average NDVI for a specific seasonal period(autumn, summer, monsoon, spring and winter). The relationship between the NDVI, and population density district-wise was analyzed using statistical methods (SPSS software).

\section{Relationship between Population Density and NDVI in Winter Season in NCR}

Fig. 2a) shows the spatial distribution of NDVI with population density during winter season of 2011. The spatial pattern of NDVI examined in relation to the general pattern of population density using NDVI maps. The month of December and January is the coldest month of the year and in these months the highest and lowest NDVI values are -0.154 and 0.821 with the mean of 0.491 . The lowest NDVI values were observed in the central parts of the study area, which are mainly covered by urban and rural built-up areas. The high NDVI values were notified in the study area north, west and south-east due to the cultivation of "Ravi" agricultural crops in these areas. It is seen that with the increase in population, there is an increase in population density. In order to house this increases population, there is a need for houses and also there are additional commercial centers. All these activities lead to the physical expansion of city meaning thereby altering the natural surface. Eastern and central part of NCR has higher constructed area and also high population density. The highest population density showed the lowest proportion of NDVI values. This leads to effects of the environmental conditions of areas.

Fig. 3a) shows a negative correlation between population density and mean NDVI of tehsil-wise over the NCR region. This means that the mean NDVI is low wherever population density is high and vice versa. This is due to the physical expansion of cities meaning thereby altering the natural surface and land conversion from agricultural to built-up area is responsible for the declining NDVI. The high negative correlation between NDVI and population density district- wise was observed in the winter season where $\mathrm{R}^{2}=(-) 0.575$. This is contrary to a positive correlation found by Bai et al. [36] over Sub-Saharan Africa between NDVI and population density. In Sub-Saharan Africa, the most fertile areas, such as mountain slopes, population density is highest [37]. The mean NDVI is low wherever population density is high suggests the role of urbanization could play an important role in land degradation and affect the ecosystems.

\section{Relationship between Population Density and NDVI in Spring Season in NCR}

Fig. 2b) shows the spatial distribution of NDVI with population density during the spring season of 2011. In the entire study area, overall high NDVI were recorded in the spring season compared to winters. However, except for the ridge forest areas (Aravali ranges), the NDVI value pattern is similar to the winter season. During, spring season the highest and lowest NDVI values were 0.859 and -0.021 with the mean of 0.521 . In the central and south-western parts of NCR, which are dominated by built-up and bare soil/exposed rocks, lower NDVI values are recorded. There is a moderate NDVI value found in the DelhiNCT surroundings, which corresponds to the fallow land.

The tehsil wise population density is shown in graduated symbol using symbol size to show the relative values. Very high population density (20001-45,384 persons/sq.km) mostly found over the NCT-Delhi area due to job opportunities and residence shifts. Whereas, the low density (353-700 persons/ sq.km) could be observed over the district of Haryana and Rajasthan Sub-region NCR areas. Fig. 3b) shows a negative correlation between population density and tehsil-wise mean NDVI over the NCR region. During the spring season, the high negative correlation between NDVI and population density was observed where $\mathrm{R}^{2}=-0.507$.

\section{Relationship between Population Density and NDVI in Summer Season in NCR}

The seasonal spatial distribution of NDVI shows that the lowest mean NDVI values (0.261) were recorded in summer season i.e. April, May, June. Some of the limiting factors for low NDVI value are climatic factors such as precipitation, solar radiation and land without crops. Fig. 2c) shows the lower NDVI values was observed in the maximum areas of NCR except in the Ganga-Yamuna river basin areas (eastern and northeastern part of NCR) and patched with ridge forest area that observed in Delhi-NCT, southern NCR near Alwar. Water shortages, agricultural crops and high thermal intensity are responsible for the lower NDVI values throughout the NCR during the summer. Fig. 3c) shows a negative correlation between population density and tehsil-wise mean NDVI over the NCR region. During the summer season, the very low negative correlation between NDVI and population density was observed where $\mathrm{R}^{2}=(-)$ 0.016. The climatic factors such as precipitation, solar radiation and land without crops are some of the limiting factors for the low negative correlation. 


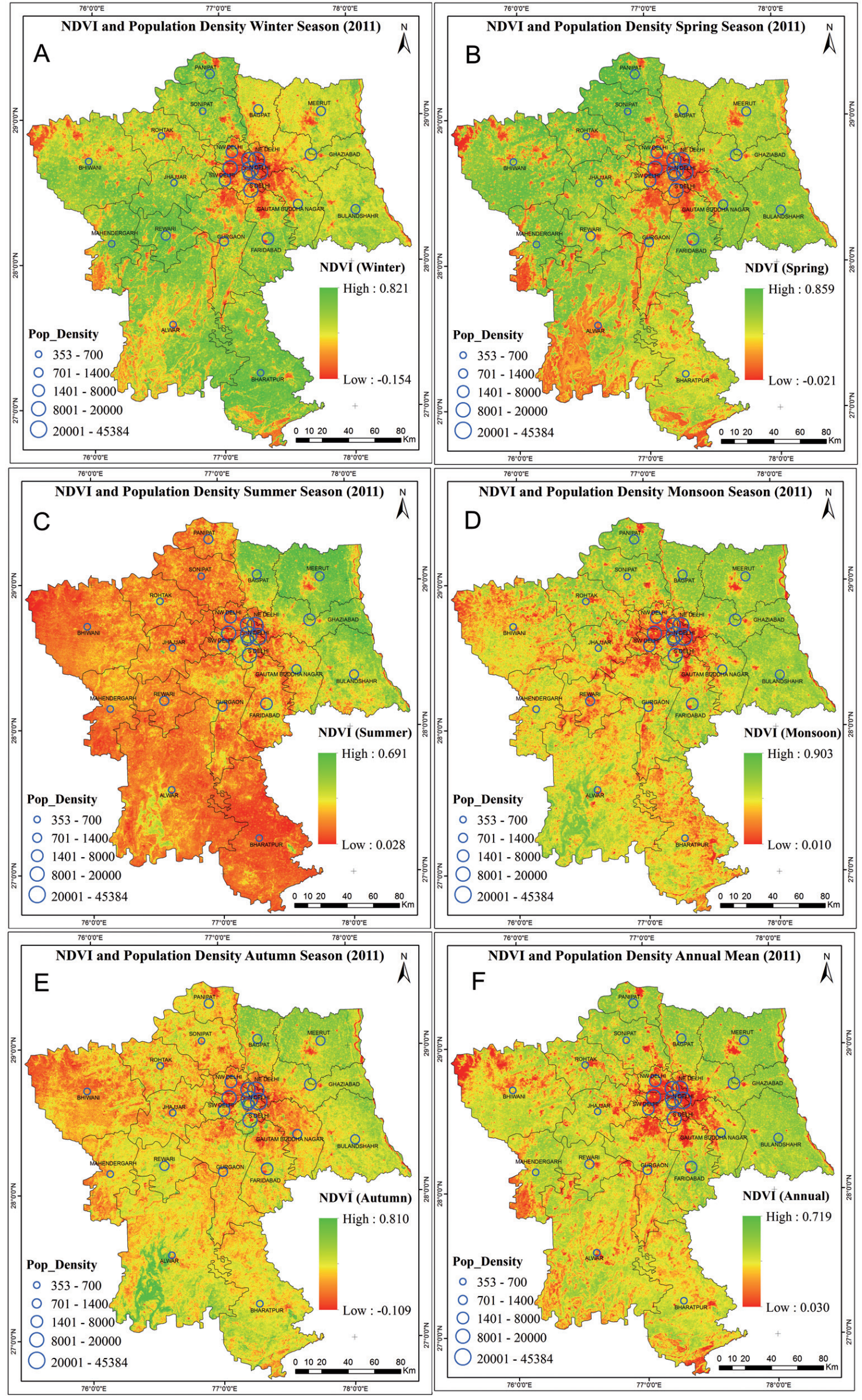

Fig. 2. Season wise-spatial distribution of NDVI with population density of 2011. 

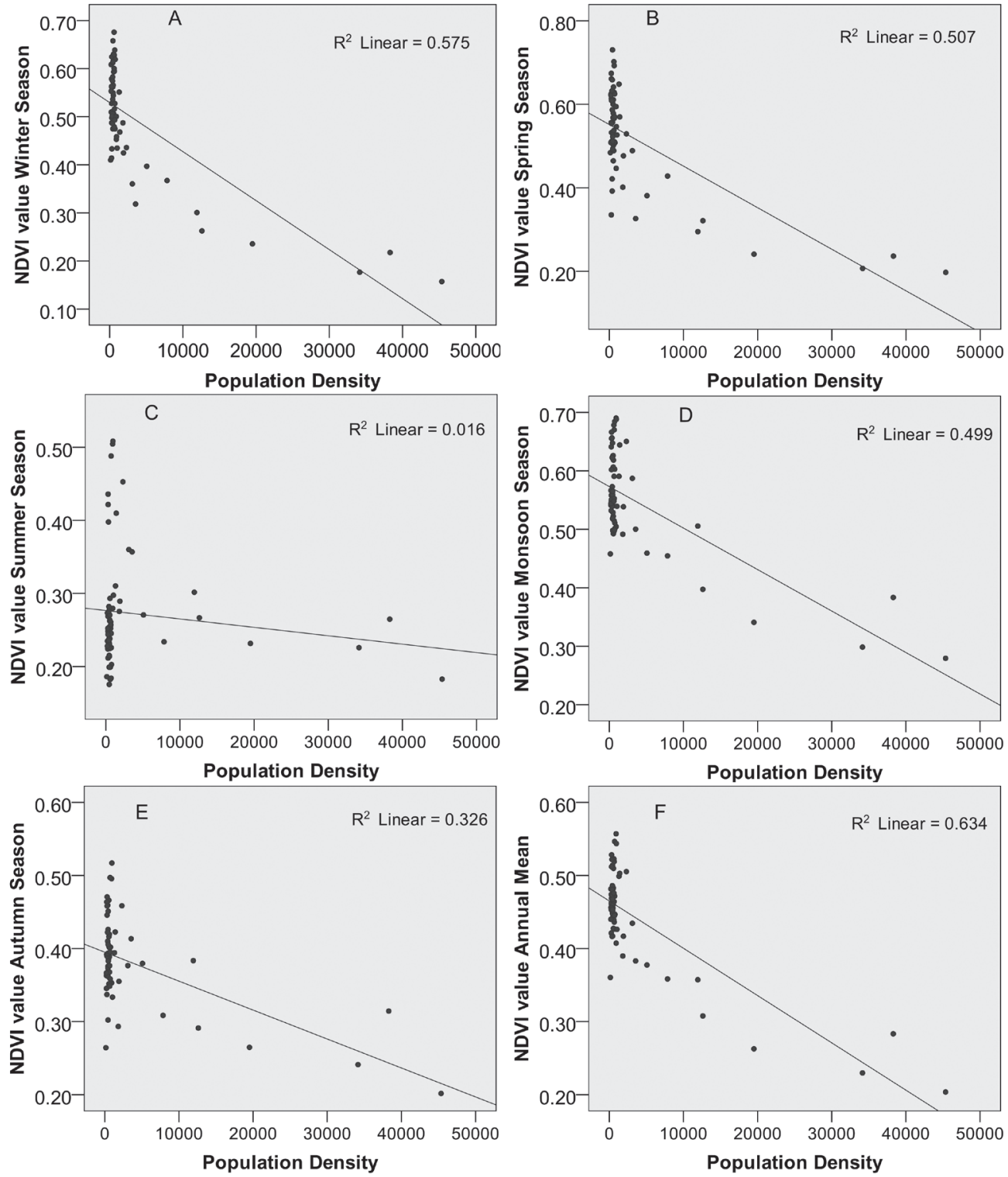

Fig. 3. Scatter plot between the NDVI-Population density (tehsil-wise) for all five seasons during 2011.

\section{Relationship between Population Density and NDVI in Monsoon Season in NCR}

Rainfall, higher temperatures and high humidity dominate in the monsoon season (July, August and September) and that's why this season's highest NDVI value is recorded. In the monsoon season, the highest and lowest NDVI values are 0.903 and 0.010 with the mean of 0.512 (Fig. 2d). Low NDVI values, however, are limited spatially to areas where population density is high throughout the cities (Delhi, Ghaziabad, Gurgaon, Meerut, Rewari, etc.). Because built-up areas are concrete and asphalt-dominated surfaces that do not maintain long-term humidity, the NDVI value has been minimized. During monsoon, when most of the city has plenty of moisture, the impermeable areas are still largely free of moisture and such surfaces appear as low NDVI areas. Temperatures drop sharply during the monsoon and post-monsoon seasons and the pattern of NDVI distribution changes significantly. Higher NDVI records the Aravali ridge forests (i.e. near Delhi, near Alwar) and other forest patches. The vegetated and agricultural cropland (Kharif crops) that dominates the eastern, north and surrounding the urban peripheries show high NDVI values. The district- wise population density is shown in graduated symbol using symbol size to show the relative values. The very low population density (353-700 persons/sq.km) mostly found over the district of Haryana and Rajasthan Sub-region NCR areas. In this season, these areas such as the eastern, north and surrounding the urban peripheries area covered by vegetated and agricultural cropland (Kharif crops). Fig. 3d) shows a negative correlation (-0.499) between population density and mean NDVI of tehsilwise over the NCR region. Wherever the population density is low, the mean NDVI is high and vice versa. 
This is due to heavy rainfall, growth of vegetation increases during the monsoon season.

\section{Relationship between Population Density and NDVI in Autumn Season in NCR}

NDVI's seasonal spatial distribution suggests that in the autumn season after summer season the lowest mean NDVI values (0.362) were recorded (Fig. 2e). This is because when autumn arrives, the photosynthesis stops, the leaves lose chlorophyll, change color and eventually fall. In the central, north-western parts of the study area, which are mainly covered by built-up land, fallow land and bare soil, the lower NDVI values were observed. NCR's east and north-east part i.e. The Ganga-Yamuna basin areas and the rocky ridge of the Aravali hills in Delhi-NCT and the southern NCR region (near Alwar) show the highest NDVI values with a linear stretch from south to northeast. Fig. 3e) shows a moderate negative correlation (-.326) between population density and mean NDVI of district-wise over the NCR region.

The overall annual mean NDVI value is ranging between 0.719 and 0.030 with the mean of 0.463 (Fig. 2f), Fig. 3f) shows a moderate negative correlation $(-0.634)$ between population density and mean NDVI of tehsil-wise over the NCR region.

\section{Season-wise Relationship between LST and Population Density in NCR}

Another very significant relationship drawn between season-wise night time surface temperature of 2011 and population density census year 2011 (Fig. 4). NightTime Surface temperature of NCR in 2011derived from MODIS LST level-3 data (MOD11A2 L3) with $1 \mathrm{~km}$ spatial resolution accessible every eight days. MODIS LST data were multiplied by a scale factor of 0.02 or $2 / 100$. This means that an LST value in the raster should be multiplied by 0.02 to reach the actual data value. Daily images were composed for the periods of four weeks (i.e. four images per month, from the $1^{\text {st }}$ day, $9^{\text {th }}, 17^{\text {th }}$ and $25^{\text {th }}$ of the month) using the maximum temperature recorded during the period. Instead of the average of four weeks, maximum LST values were used to ensure the minimum effect of cloud coverage on our data. Whereas seasonal land surface temperature was obtained using average temperature for a specific seasonal period (viz. "autumn = October and November; winter $=$ December and January; spring = February and March; summer = April, May, June and monsoon = July, August and September"). Using statistical methods (SPSS software), the relationship between season-wise Nightime LST and population density of tahsil wise (sub-districts-wise) data was analyzed. The 2011 population density data obtained from the census of India was represented by proportional symbols and was categorized into five classes from very high to very low, since population density is one of the key factors for increasing the surface temperature of the area.

\section{Relationship between LST and Population Density in Winter Season in NCR}

The seasonal spatial distribution of surface temperature shows that the lowest surface temperature was recorded in winter season i.e. December and January, the coldest month of the year. In winters (December-January), LST ranges between $7.11^{\circ} \mathrm{C}$ and $16.17^{\circ} \mathrm{C}$ with a mean of $11.02^{\circ} \mathrm{C}$. The distribution of lowest temperature could be observed in the eastern and northern parts of the study area, mainly covered by agricultural land (under the Rabi crop), sparse and dense vegetation, and rural development. Because of the low thermal capacity of barren land and wasteland/ barren soil, it cools faster than other features of LULC. It is, therefore, cooler than other LULC during the night when compared to other LULC. The urban land which is mainly in the central eastern parts of cities shows higher temperature conditions. The built-up rural land is similar to the built-up urban land but having lower land surface temperature compared to the big urban area may be due to the densely built-up land in the areas (Fig. 4a). The rocky ridge of Aravali hills in southern NCR with linear stretch from south to north and east directions with some forest patches also shows the high surface temperature. The analysis of the spatial distribution of night-time surface temperature within the urban areas indicates that built-up having higher surface temperature compare to other LULC classes. Such built-up areas are primarily due to increased economic activity and the rapid growth of suburban communities in order to provide accommodation for the increasing population. This raises the population density and, in effect, results in higher surface or urban temperatures in that particular area.

The high densities of population and frequent human activities contribute to the change in surface temperature and that leads to change in thermal environmental conditions of the cities found over the NCR. A relationship between night-time surface temperature during the winter season and population density was drawn (Fig. 5a) the figure shows a high positive co-relationship between these two because the value of logarithmic regression $\left(\mathrm{R}^{2}\right)$ is 0.554 (Table 2). It means that surface temperature also increases with the increase in population density. It is therefore possible to forecast surface temperatures during the night based on the known population density.

\section{Relationship between LST and Population Density in Spring Season in NCR}

In all parts of the study area, the overall high temperature was recorded in the spring season compared to winter. The land surface temperature pattern, however, is similar to the winter season. During the spring season, night-time LST ranges between 


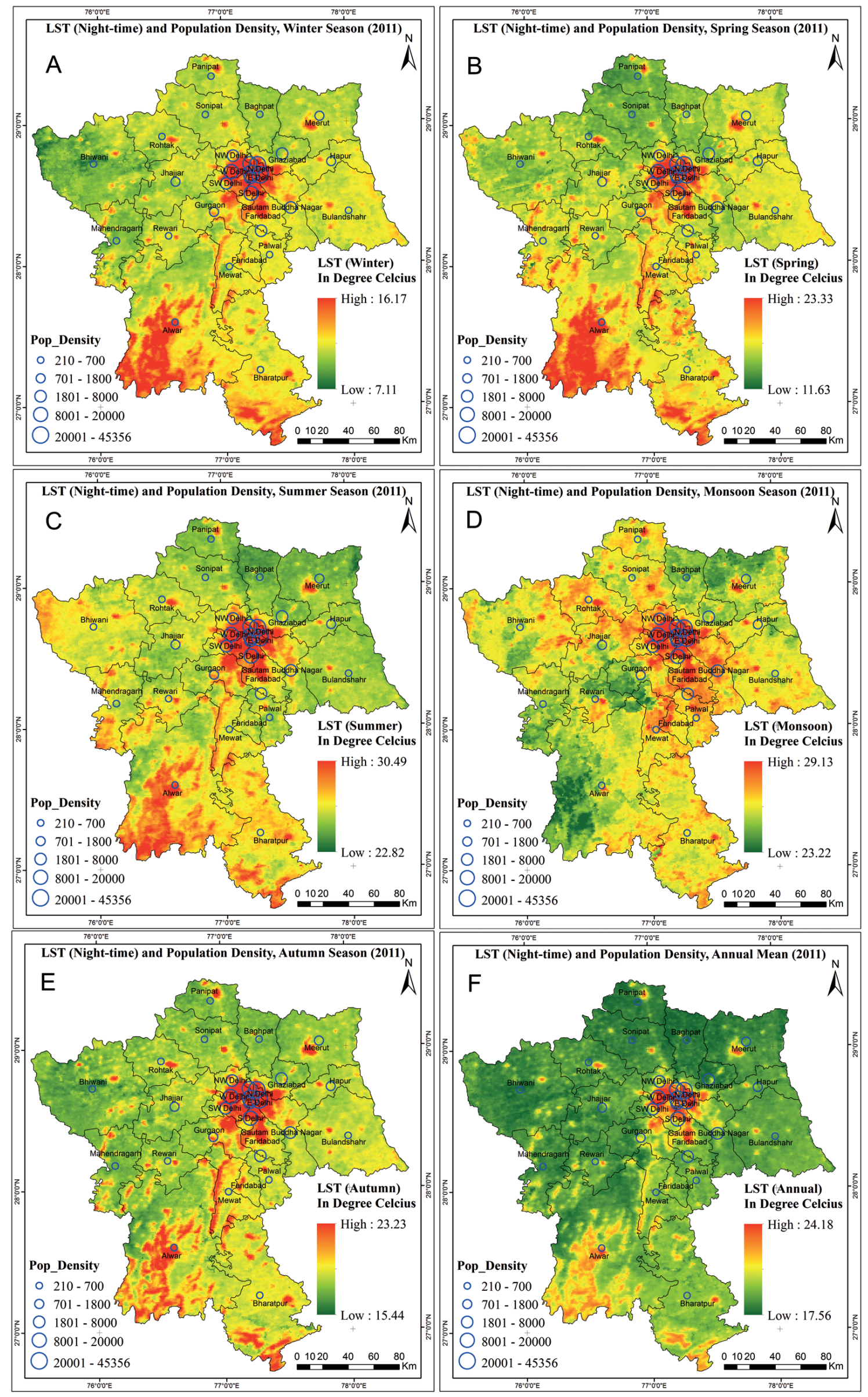

Fig. 4. Season wise-spatial distribution of Night-time LST with population density of 2011 . 
$11.63^{\circ} \mathrm{C}$ to $23.33^{\circ} \mathrm{C}$ with the mean of $16.81^{\circ} \mathrm{C}$. The spatial distribution of lower temperature during spring season could be observed in north, northwest and western parts of NCR namely districts of Haryana Sub-region such as Panipat, Sonipat, Rohtak, Bhiwani and in UP subregion such Baghpat. This is due to the dominance of scrublands, fallow lands, and sparse vegetation. Because of the low thermal capacity of scrublands, barren land and wasteland/barren soil, it cools faster than other LULC features such as built-up and exposed rocky surfaces. Whereas, the built-up urban land (Gurgaon, southeast: south Delhi and airport's open area of NCTDelhi) and Aravali range's rocky surfaces record this season's highest temperatures (Fig. 4b). A relationship between night-time surface temperature during the spring season and population density was drawn (Fig. 5b) the figure shows a moderate positive corelationship between these two because the value of logarithmic regression $\left(\mathrm{R}^{2}\right)$ is 0.467 (Table 2).

\section{Relationship between LST and Population Density in Summer Season in NCR}

The study shows that during the summer season, the temperature rises sharply and the pattern of spatial temperature distribution changes significantly. During the summer season, night-time LST ranges between $22.82^{\circ} \mathrm{C}$ to $30.49^{\circ} \mathrm{C}$ with the mean of $25.66^{\circ} \mathrm{C}$. The dominance of scrublands, fallow lands, and sparse vegetation shows the lower surface temperature at night-time and this mostly located in the U.P sub-region NCR's district. It could be observed in the northern, north-eastern and eastern part of NCR. This is due to the low thermal capacity of features mentioned above; it cools faster than other LULC features i.e. built-up and exposed rocky surfaces. It is important to note that areas with the highest summer temperature in day time experienced the lowest surface temperature at night time. There is also intense heating in the over
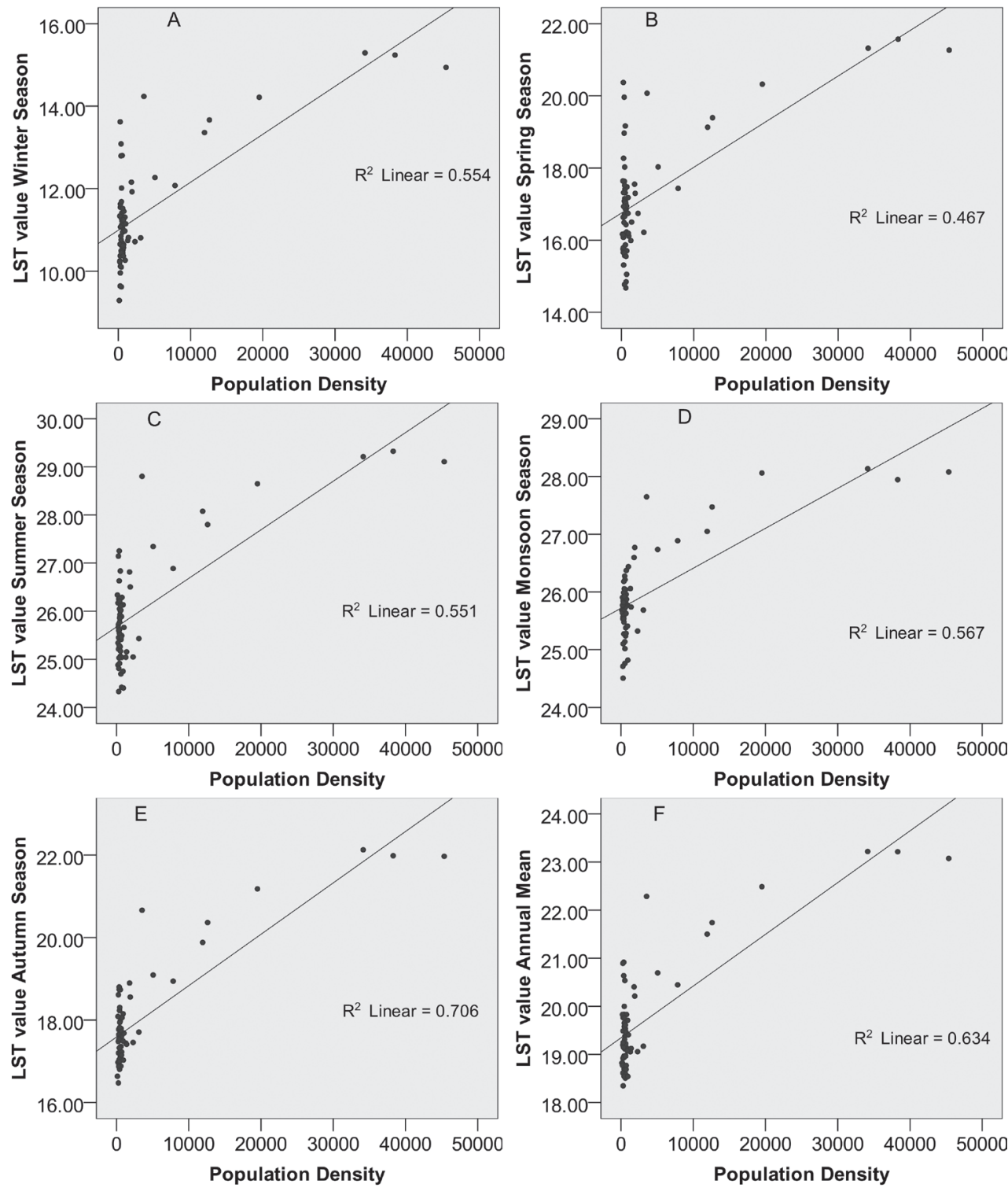

Fig. 5. Scatter plot between the night-time LST-Population density (tehsil-wise) for all five seasons during 2011. 
Table 2. Season-wise correlation between Night-time LST and Population Density (Tehsil-wise) (2011).

\begin{tabular}{|c|c|c|c|}
\hline Seasons & & LST & Population Density \\
\hline \multirow{3}{*}{ Winter Seasons } & LST & 1.000 & $0.554^{*}$ \\
\cline { 2 - 4 } & PopDen & $0.554^{*}$ & 1.000 \\
\hline \multirow{3}{*}{ Spring Seasons } & LST & 1.000 & $0.467^{*}$ \\
\cline { 2 - 4 } & PopDen & $0.467^{*}$ & 1.000 \\
\hline \multirow{2}{*}{$\begin{array}{c}\text { Monsoon } \\
\text { Seasons }\end{array}$} & LST & 1.000 & $0.567^{*}$ \\
\cline { 2 - 4 } $\begin{array}{c}\text { Summer } \\
\text { Seasons }\end{array}$ & PopDen & $0.567^{*}$ & 1.000 \\
\cline { 2 - 4 } & PopDen & 1.000 & $0.467^{*}$ \\
\hline \multirow{2}{*}{$\begin{array}{c}\text { Autumn } \\
\text { Seasons }\end{array}$} & LST & 1.000 & 1.000 \\
\cline { 2 - 4 } & PopDen & $0.706^{*}$ & 1.000 \\
\hline \multirow{2}{*}{\begin{tabular}{c} 
Annual \\
\cline { 2 - 4 }
\end{tabular}} & LST & 1.000 & $0.634^{*}$ \\
\cline { 2 - 4 } & PopDen & $0.634^{*}$ & 1.000 \\
\hline
\end{tabular}

*Correlation is significant at 0.05 level of significance (1-tailed)

barren land, rocky surfaces and built-up land. The hot spots of build-up land could easily identify in the map (Fig. 4c). The figure shows that the high surface temperature is more in the rocky ridge of Aravali hills in southern NCR with linear stretch from south to north and east directions and central part of the NCT and Urban center in NCRs corresponding to buildup area. NCR sub-region wise analysis shows that the Rajasthan Sub-region's districts having higher LST compared to the other NCR sub-regions this is due to the closeness to the Thar Desert, scarcity of vegetation and also agricultural fallow land. The major cities showing higher temperature as compared to other land cover classes. A relationship between night-time surface temperature during the summer season and population density was drawn (Fig. 5c) the figure shows a high positive co-relationship between these two because the value of logarithmic regression $\left(\mathrm{R}^{2}\right)$ is 0.551 (Table 2) and it is higher than the spring season.

\section{Relationship between LST and Population Density in Monsoon Season in NCR}

Rainfall and high air humidity dominate the monsoon season (July, August and September). During monsoon season, night-time LST ranges between $23.22^{\circ} \mathrm{C}$ to $29.13^{\circ} \mathrm{C}$ with the mean of $25.71^{\circ} \mathrm{C}$. The highest land surface temperature has been observed during the monsoon season as compared to the other seasons. This is despite the fact that there is the highest rainfall in the monsoon season. However, high land surface temperature values are spatially limited to build up areas almost in every city (Delhi, Ghaziabad, Gurgaon, Meerut, Rewari, etc.). This is due to the incoming short wave incident at the rural site is higher during the monsoon (Fig. 4d), perhaps because the urban area is a continuous source of high anthropogenic emissions of aerosols and low urban albedo. This also led to the high thermal capacity that the build-up material releases the heat slowly during the night. Secondly, built-up areas are concrete and asphalt-dominated surfaces that do not maintain long - term moisture.

During monsoons, when there is plenty of moisture on most land surfaces, the impermeable areas are still relatively free of moisture and surfaces e.g. high surface temperature areas with high intensity. The north-eastern, western (western side of Rewari), central and south-western parts of the NCR under the NCR's districts namely Baghpat, Meerut, Alwar and Mahendragarh, which are predominantly scrubland/ fallow land, and barren land, have the lowest LST. It is important to note that areas with the highest summer temperature experienced the lowest monsoon temperature and therefore, the lowest temperature range compared to summer season due to increased greenness and thermal capacity, resulting in high-level cooling. A relationship between night-time surface temperature during monsoon season and population density was drawn (Fig. 5d) the figure shows a high positive corelationship between these two because the value of logarithmic regression $\left(\mathrm{R}^{2}\right)$ is 0.567 (Table 2).

\section{Relationship between LST and Population Density in Autumn Season in NCR}

In every part of the study area, overall high temperature found in the autumn season compared to monsoon season (Fig. 4e). During the autumn season, night-time LST ranges between $15.44^{\circ} \mathrm{C}$ to $23.23^{\circ} \mathrm{C}$ with the mean of $17.63^{\circ} \mathrm{C}$. However, the pattern of land surface temperature is similar to the summer season, but the temperature compared to the summer season was low. The autumn season's high surface temperature pattern is similar to that of the summer season, as the centre part of the cities in NCR sub-regions shows high temperatures on the surface. But the autumn season's high night-time surface temperature areas are relatively smaller than summer. In autumn, central portions bear elevated temperature, with the maximum reaches in NCT-Delhi and urban areas in NCR.

The rocky ridge of Aravali hills in southern NCR also shows the high surface temperature with a linear stretch from south to north and east with some scrubland areas. Analysis of the spatial distribution of night-time surface temperature in urban areas shows that the built-up temperature is higher than in other LULC classes. These dense built-up areas are primarily due to the growth of economic activities and the rapid development of residential societies to provide housing to the growing population. During autumn seasons, the NCT-Delhi and Rajasthan sub-region NCR having higher surface temperature during night-time, whereas, Haryana U.P sub-region and U.P sub-region found the 
lower temperature. This difference found due to the built-up land and exposed rocks (geological structures) extensively located in NCT-Delhi and Rajasthan subregion NCR. A relationship between night-time surface temperature during the autumn season and population density was drawn (Fig. 5e), the figure shows a very high positive co-relationship between these two because the value of logarithmic regression $\left(\mathrm{R}^{2}\right)$ is 0.717 (Table 2). The correlation was found very high as compared to all other four seasons.

\section{Relationship Annual Mean LST and Population Density in NCR}

The annual land surface temperature was obtained using average temperature for all the seasonal period. Using statistical methods (SPSS software), the relationship between annual nighttime LST and population density of tahsil wise (sub-districts-wise) data was analyzed. The study shows that the annual night-time LST ranges between $17.56^{\circ} \mathrm{C}$ to $24.18^{\circ} \mathrm{C}$ with a mean of $19.36^{\circ} \mathrm{C}$. The dominance of scrublands, fallow lands, and sparse vegetation shows the lower surface temperature at night-time and this mostly located throughout the NCR sub regions except for NCT-Delhi, urban areas and southern ridge area located in Rajasthan sub-region. This is due to the low thermal capacity of features mentioned above; it cools faster than other LULC features i.e. built-up and exposed rocky surfaces. It is important to note that areas with the highest surface temperature in day time experienced the lowest surface temperature in night time. In the barren land, rocky surfaces and built-up land, there is also intense heating. The building land hot spots (highly urbanized areas) could be easily identified in the map (Fig. 4f). The figure shows that the high surface temperature is more in the rocky ridge of Aravali hills in southern NCR with linear stretch from south to north and east directions and central part of the NCT and Urban centre in NCRs that correspond to build-up area. Such urban areas are largely due to increased economic growth and increasing development of suburban communities to provide accommodation for the rising population. High population density, which in turn contributes to higher surface or urban temperatures in that particular region. NCR sub-region wise analysis shows that the Rajasthan Sub-region's districts and NCT-Delhi having higher LST compared to the other NCR sub-regions this is due to the rocky land, scarcity of vegetation and also more agricultural fallow land. A relationship between annual night-time surface temperature and population density was drawn (Fig. 5f), the figure shows a very high positive co-relationship between these two because the value of linear regression $\left(\mathrm{R}^{2}\right)$ is 0.634 (Table 2).

A function of population growth could explain the substantial amount of variance in temperature rise in cities. The growing cities demonstrated the highest warming rates and the most representative factors in population density for the urban contribution to temperature change. The study shows a clear link between population density, vegetation (NDVI), builtup area and surface temperature. Statistical analysis of night surface temperature with population density shows that population growth tends to contribute to urban surface temperature and also affect NCR's environmental conditions.

\section{Discussion}

This research was done to evaluate the seasonal characteristics of land surface temperature with NDVI and population density. Previous studies of night-time land surface temperature with population density studies were performed of Delhi using ASTER datasets [38]. In addition, a number of seasonal characteristics of land surface temperature with NDVI and population density studies have been conducted using geoinformation techniques [39, 40]. In their analysis, Singh et al. [39] examined a time series of statistical data for 40 years (1967 to 2007) in Dehradun, India and developed LUCC spatial distribution trends and identified that population distribution was influenced by the degree of comfort (measured by temperature) of the residential environment. Li et al., [40] studied that in suburban areas, the association between population density and LST values. In their analysis, the high-LST regions were focused on low vegetation covered residential and industrial areas and the population density (PD) had impacts on the LST values in the residential area. Weng and Yang [19] examined the potentially negative thermal effects of urban growth in Guangzhou, China during the summer and winter seasons.

Growth in populations in marginal areas puts pressure on land resources, leading to environmental problems. Social characteristics of population distribution and population density are one of the indirect factors which play an important role for understanding and assessment of environmental change of a region. A function of population growth could explain the substantial amount of variance in vegetation cover (NDVI) in regions. The growing urban areas demonstrated the highest warming rates and the most representative factors in population density for the urban contribution to temperature change. The study shows a clear link between population density, vegetation (NDVI), built-up area and surface temperature. It is seen that with the increase in population, there is an increase in population density. In order to house this increases population, there is a need for houses and also there is additional commercial centers. All these activities lead to physical expansion of city meaning thereby altering the natural surface. Eastern and central part of NCR has higher constructed area and also high population density. The highest population density showed the lowest proportion of NDVI values. This leads to effects the environmental conditions of areas. The study shows a negative correlation between population density and 
Table 3. Research findings relationships between LST, LULC and NDVI.

\begin{tabular}{|c|c|c|c|}
\hline Data & Study area & Authors & Results \\
\hline $\begin{array}{c}\text { Landsat-TM, Landsat- } \\
\text { ETM+, Landsat-8 }\end{array}$ & Delhi, India & {$[8,22-25]$} & $\begin{array}{c}\text { Vegetation had a notable cooling effect as the normalized vegetation } \\
\text { difference index (NDVI) increased. LST-NDVI showed a negative } \\
\text { correlation }\end{array}$ \\
\hline $\begin{array}{c}\text { Landsat-TM \& Landsat- } \\
\text { ETM+ }\end{array}$ & South Karkheh, Iran & {$[42]$} & Negative correlation between LST-NDVI \\
\hline Landsat-TM & Shiraz City, Iran & {$[43]$} & The negative correlation between vegetation and LST \\
\hline Landsat-TM & Guilin, China & {$[44]$} & Negative correlation between LST-NDVI \\
\hline Landsat-8 & Guizhou, China & {$[45]$} & $\begin{array}{c}\text { "LST and NDVI scatter plots showed an obtuse-angled triangle } \\
\text { distribution" }\end{array}$ \\
\hline ASTER & Abha, Saudi Arabia & {$[46,47]$} & $\begin{array}{c}\text { LST-NDVI showed a negative correlation } \\
\text { MODIS }\end{array}$ \\
\hline Arabia & {$[48]$} & $\begin{array}{c}\text { Seasonal Day-Night LST analysis, Strongest correlation found } \\
\text { during autumn season }\end{array}$ \\
\hline
\end{tabular}

mean NDVI of district-wise over the NCR region. This means that the mean NDVI is low wherever population density is high and vice versa. This is due to physical expansion of cities meaning thereby altering the natural surface and land conversion from agricultural to built-up area is responsible for the declining NDVI. The highest negative correlation between NDVI and population density tehsil wise was observed in the winter season where $R^{2}=(-) 0.575$. This is contrary to a positive correlation found by Bai et al. [36] over SubSaharan Africa between NDVI and population density. In Sub-Saharan Africa, the most fertile areas, such as mountain slopes, population density is highest [37]. The mean NDVI is low wherever population density is high suggests the role urbanization could play an important role in land degradation and affect the ecosystems.

The seasonal distribution of surface temperature shows that the lowest surface temperature was recorded in winter season whereas the highest temperature was recorded in summer season. The lowest temperature during winter season could be observed in the eastern and northern parts of the study area, mainly covered by agricultural land (under the Rabi crop), sparse and dense vegetation, and rural development. Vegetation had a notable cooling effect as the normalized vegetation difference index (NDVI) increased during summer [41]. This is because of the low thermal capacity of barren land and waste land/barren soil; it cools faster than other features of LULC.

On the contrary, during summer, there is also intense heating in the over barren land, rocky surfaces and built-up land. Baresoil contributes to low vegetation cover Tian et al. [49], surface water infiltration, human intrusion and degradation causes extreme soil erosion [18], loss of water [50], resulting in exposed rock and rocky desertification [51]. Specific heat capacity and thermal inertia of surface substances were low. The LST area grew rapidly throughout the day and was higher in the surrounding area, creating an unusually high LST region. The LST of the exposed rocky areas characterized not only by the classical urban thermal influence, but also by the extreme high LST zone aggravated by the rocky area desertification [47]. In future research, LST will be used as a critical item and index to analyze and assess the degree of desertification in rocky areas. The hot spots of build-up land could easily identify in the map (Fig. 6c). The figure shows that the high surface temperature is more in the rocky ridge of Aravali hills in southern NCR with linear stretch from south to north and east directions and central part of the NCT and Urban centre in NCRs that correspond to build-up area. These build-up areas are primarily due to increased economic activity and rapid development of residential societies to provide houses to the growing population. Increased population density, which in turn contributes to higher surface or city temperatures in that particular area.

Statistical analysis of night-time LST with population density demonstrates that population growth tends to contribute to urban LST and also affect the environmental conditions of NCR. An increasing amount of population concentration (growth pressure) in NCR is maximum; as a result temperature is increasing automatically. The substantial amount of the variance of temperature at city level has been explained by a function of population density. The highest population density cities showed the highest warming rates. The strong positive co-relationship established between night-time surface temperature and population density. The increase in population density leads to the increase in surface temperature directly. Because population is linked to number of house units, with the increase in population density, more houses are needed and this leads to high built-up density. In order to build house units to support this increases population, there is a need for more house units and also there is additional community centres. All these activities lead to physical expansion of city meaning thereby increase in built-up/ impervious areas consequently surface temperature of that area is grownup. The results of the study found 
that the relationship between urban built-up areas and LST was positive, consistent with Rotjanakusol and Laosuwan [52] findings.

As the most crucial factors for the urban contribution to climate change [53], the increasing cities reported the highest warming levels and square root of population size. Oke [28], used the empirical method to represent the relationship between urban and rural temperatures as population concentration. Separating many contributors to the problem isn't easy. However, the population density of major cities [54] is one of the most notable and very strong correlations with the UHI phenomenon or urban surface temperature.

When cities continue to grow and climate warms, urban thermal stress risks increase $[6,55]$. Crowdedness caused by urbanization in NCR is likely to come in the future. This situation will have negative consequences in the area due to the associated problems, the environmental condition of urban areas, crowdedness such as crime and easy disease spread. It is therefore suggested that people should be encouraged to construct their building areas towards the outskirts by providing incentives and attractive forces available in these areas in the city centre. It was noted that urban unplanned construction, along with unauthorized colonies, resulted in high surface temperatures. The free circulation of airspace thus helps to understand the spatial pattern of the diverse thermal environment phenomenon by separating, planning and open space. Remote sensing imaging can effectively evaluate the thermal behavior of each LU/LC class and the thermal effect of the spatial pattern of the LU/LC classes to derive geospatial information, thereby, helping to plan and design urban climate.

In order to improve the survival rate and proper plant growth, it is also necessary to identify pollutanttolerant tree species in polluted hotspots in urban areas of NCR. The results of this study can be used as a reference for urban planners to eco-friendly urban planning. The government encourages the planting of small trees instead of large-scale varieties because of management difficulties and for safety reasons. In contrast, many planners and researchers have focused on urban vegetation, such as roadside trees, urban parks and urban forests, as an effective method of controlling urban temperatures and air quality, as urban thermal environments have become one of the environmental challenges. Coutts et al. [56] and Zhou et al. [57] stated that the location of trees, the characteristics of the urban canyon and whether single or multiple trees are planted affect their cooling potential. The pragmatic solution to environmental change is to take a wide range of measures to control emission levels, effect and encourage scientific, technological and socio-economic research. From remote sensing images it was observed that trees that are systematically planted along the water bodies channel, road and green public parks have low temperatures. It therefore emphasized the relevance of trees in reducing thermal and recreational areas in the urban area. As concerns the Yamuna River, is concerned, the river must be cleaned (restored), development and restoration of river banks as a biodiversity area, point source water pollution reduction due to anthropogenic activity and Industrial residues. It therefore affects water pollution and indirectly increases temperature.

\section{Conclusions}

This research is of utmost importance because it relies on understanding the temporal relationship between $\mathrm{LU} \backslash \mathrm{LC}$ land surface temperature dynamics and vegetation cover (NDVI) over the five seasons in the NCR. Vegetation cover and population density and its variability characteristics in NCR has major effects on thermal environments, mainly on LST, and quantitative analyzes were investigated to demonstrate the relationship between NDVI, population density and LST in urban areas. Satellite images from MODIS and LANDSAT 8 were used to obtain maps of land coverage classification, NDVI and LST to determine the impact of those parameters on LST variability. The results inferred that the temporal and spatial pattern of LST distribution in the NCR is significantly diverse.

Several conclusions can be drawn from this study.

1. The coldest month shows lower LST over all types of land use/land cover, but the highest temperature is accounted for the summer month. For scrubland/ fallow land areas and agricultural land, the difference between the maximum and minimum temperature is the highest for all seasons, mainly corresponding to NCR Cities' peripheral areas.

2. This means where NDVI is high, the land surface temperature is low and vice versa. The high LST-NDVI negative correlation was observed in the monsoon season where $\mathrm{R}^{2}=(-0.5503)$.

3. Statistical analysis of nighttime LST with population density shows that population growth tends to lead to urban LST rise or UHI strength, as well as effects NCR micro-climate.

4. There are very few meteorological stations to record the surface temperature in earlier periods, and they may not be the true representation for the entire region. In these cases, LST derived from thermal satellite data is useful for studying the variation of LST over the whole wide region such as NCR, an important parameter for urban micro-climate.

5. This analysis clearly demonstrates LST spatial variability over entire NCR. By superimposing the population density over the surface temperature, it is evident that high population density is one of the key contributing factors for NCR's high surface temperature, UHI intensity and also micro-climate. To evaluate and resolve the micro-climate problem and to reduce the effect of UHI on the urban population, the results of these studies may be useful. 
The study findings provide data supporting NCR's urban planning and environmental research. However, the remote sensing image is easily limited by the cloud cover effect, which adversely affects DN values, and the satellite's limited revisiting cycle for the pixel site. Thus, future research will concentrate on integrating the long-term data sets to analyze the effects of land surface temperature mechanics for land use/land cover, vegetation cover (NDVI) population density in the National Capital Region (NCR), India and also to analyze the thermal environment of different NCR Indian cities and comparing their urban thermal behaviour. It is also recommended that future research will carry out to examine the advanced capability of the thermal remote sensing over vegetated cover areas in relation to the other urban landscape. In this, it is also suggested that advanced urban landscape research should be carried out to evaluate the capacity to utilize the thermal remote sensing over vegetated areas including estimation of surface temperature and its effect on the environment.

\section{Acknowledgements}

The authors extend their appreciation to the Deanship of Scientific Research at King Khalid University for funding this work through General Research Project under grant number (R.G.P2 /92/41).

\section{Conflict of Interest}

The authors declare no conflict of interest.

\section{References}

1. CHEN F., YANG S., YIN K., CHAN P. Challenges to quantitative applications of Landsat observations for the urban thermal environment. Journal of Environmental Sciences, 59, 80, 2017.

2. MALLICK J., SINGH C.K., SHASHTRI S., RAHMAN A., MUKHERJEE S. Land surface emissivity retrieval based on moisture index from LANDSAT TM satellite data over heterogeneous surfaces of Delhi city. Int. J. Appl. Earth Obs. Geoinf. 19, 2012.

3. MALLICK J., KANT Y., BHARATH B.D. Estimation of land surface temperature over Delhi using Landsat ETM+, Journal of Indian Geophysical Union, (July 2008) 12 (3), 131, 2008.

4. $\quad$ LI Z.-L., TANG B.-H., WU H., REN H., YAN G., WAN Z., SOBRINO J.A. Satellite derived land surface temperature: Current status and perspectives. Remote Sensing of Environment, 131, 14, 2013.

5. NDOSSI M.I., AVDAN U. Inversion of Land Surface Temperature (LST) Using Terra ASTER Data: A Comparison of Three Algorithms. Remote Sens. 8, 993, 2016.

6. OLESON K.W., MONAGHAN A., WILHELMI O., BARLAGE M., BRUNSELL N., FEDDEMA J., HU L., STEINHOFF D.F. Interactions between urbanization, heat stress, and climate change. Clim Change 129 (3-4), 525, 2015.

7. MITCHELL J.M. The temperature of cities. Weather-wise, 14, 224, 1961.

8. HANG H.T., RAHMAN A. Characterization of thermal environment over heterogeneous surface of National Capital Region (NCR), India using LANDSAT-8 sensor for regional planning studies. - Urban Climate 24, 1, 2018. DOI: 10.1016/j.uclim.2018.01.001

9. SINGH R.B., KUMAR D. Remote sensing and GIS for land use/cover mapping and integrated land management: Case from the middle Ganga plain. Front. Earth Sci. 6, 167, 2012.

10. LI Z., XIE C., CHEN D., LU H., CHE S. Effects of land cover patterns on land surface temperatures associated with land use types along urbanization gradients in Shanghai, China. Polish J. Environ. Stud. 29 (1), 2020.

11. VALSSON S., BHARAT A. Urban Heat Island: Cause for Microclimate Variations. Architecture-Time Space \& People, April 2009, 21, 2009.

12. KUANG W., LIU Y., DOU Y., CHI W., CHEN G., GAO C., YANG T., LIU J., ZHANG R. What are hot and what are not in an urban landscape: Quantifying and explaining the land surface temperature pattern in Beijing, China. Landsc. Ecol. 30, 357, 2015.

13. OWEN T.W., CARLSON T.N., GILLIES R.R. Remotely sensed surface parameters governing urban climate change: Internal Journal of Remote Sensing. 19, 1663, 1998.

14. DENG X.Z., HUANG J.K., LIN Y.Z., SHI Q.L. Interactions between climate, socio-economics, and land dynamics in Qinghai Province, China: A LUCD model-based numerical experiment. Adv. Meteorol. 2013, doi:10.1155/2013/297926.

15. SINGH R.B., GROVER A., ZHAN J. Inter-seasonal variations of surface temperature in the urbanized environment of Delhi using Landsat thermal data. Energies. 7, 1811, 2014.

16. PANDEY P., KUMAR D., PRAKASH A., KUMAR K., JAIN V.K. A study of the summertime urban heat island over Delhi. Int. J. Sustain. Sci. Stud., 1, 27, 2009.

17. LI Y.Y., ZHANG H., KAINZ W. Monitoring patterns of urban heat islands of the fast-growing Shanghai metropolis, China: Using time-series of Landsat TM/ETM+ data. Int. J. Appl. Earth Obs. Geoinf. 19, 127, 2012.

18. MALLICK J., RAHMAN A., SINGH C.K. Modeling urban heat islands in heterogeneous land surface and its correlation with impervious surface area by using nighttime ASTER satellite data in highly urbanizing city, DelhiIndia. Adv. Space Res. 52, 639, 2013.

19. WENG Q., YANG S. Managing the adverse thermal effects of urban development in a densely populated Chinese city. J. Environ. Manag, 70, 145, 2004

20. ZHANG H., QI Z.F., YE X.Y., CAI Y.B., MA W.C. Analysis of land use/land cover change, population shift, and their effects on spatiotemporal patterns of urban heat islands in metropolitan Shanghai, China. Appl. Geogr. 44, 121, 2013

21. BRASWELL B. H., SCHIMEL D. S., LINDER E., AND MOORE B. The response of global terrestrial ecosystems to interannual temperature variability. Science, $\mathbf{2 3 8}, 870$, 1997.

22. SHARMA R., JOSHI P.K. Identifying seasonal heat islands in urban settings of Delhi (India) using remotely sensed data - an anomaly based approach. Urban Climate 9, 19, 2013 
23. KUMARI B., MOHAMMAD T., MALLICK J., KHAN F., RAHMAN A. Satellite-Driven Land Surface Temperature (LST) Using Landsat 5, 7 (TM/ETM+ SLC) and Landsat 8 (OLI/TIRS) Data and Its Association with Built-Up and Green Cover Over Urban Delhi, India. Remote Sensing in Earth Systems Sciences, 1, 2018.

24. GROVER A. SINGH R.B. Analysis of Urban Heat Island (UHI) in Relation to Normalized Difference Vegetation Index (NDVI): A Comparative Study of Delhi and Mumbai. Environments, 2, 125, 2015.

25. SINGH R.B., GROVER A. Spatial correlations of changing land use, surface temperature(UHI) and NDVI in Delhi using Landsat satellite images. In Urban Development Challenges, Risks and Resilience in Asian Megacities; Singh, R.B., Ed.; Springer: Tokyo, Japan, 83, 2015.

26. WENG Q., LU D., SCHUBRING J. Estimation of land surface temperature-vegetation abundance relationship for urban heat island studies, Remote Sensing of Environment, 89 (4), 467, 2004.

27. POTTER C.S., BROOKS V. Global analysis of empirical relations between annual climate and seasonality of NDVI. International Journal of Remote Sensing, 15, 2921, 1998.

28. OKE T.R. City size and the urban heat island. Atmospheric Environment 7 (8), 769, 1973.

29. KARL T.R., DIAZ H.F., KUKLA G. Urbanization: Its detection and effect in the United States climate record. Journal of Climate 1, 1099, 1988.

30. PETERSON T.C., GALLO K.P., LAWRIMORE J., OWEN T.W., HUANG A., MCKITTRICK D.A. Global rural temperature trends. Geophys. Res. Lett., 26, 329, 1999.

31. DING H., SHI W. Land-use/land-cover change and its influence on surface temperature: A case study in Beijing city. Int. J. Remote Sens. 34, 5503, 2013.

32. ZHANG H., QI Z.-F., YE X.-Y., CAI Y.-B., MA W.-C. Analysis of land use/land cover change, population shift, and their effects on spatiotemporal patterns of urban heat islands in metropolitan Shanghai, China. Appl. Geogr., 44, 121, 2013.

33. ELEFTHERIOU D., KIACHIDIS, K., KALMINTZIS G., KALEA A., BANTASIS C., KOUMADORAKI P., SPATHARA M.E.,TSOLAKI, A., TZAMPAZIDOU M.I., GEMITZI A. Determination of annual and seasonal daytime and nighttime trends of MODIS LST over GreeceClimate change implications. Sci. Total Environ. 616, 2017.

34. HELLDEN U., TOTTRUP C. Regional desertification: A global synthesis, Global and Planetary Change 64, 169, 2008.

35. CENSUS OF INDIA. Provisional Population Totals, Paper 1 of 2011 India, Series-1, Office of the Registrar General \& Census Commissioner, New Delhi, 2011.

36. BAI Z. G., DENT D. L., OLSSON L., SCHAEPMAN M. E. Proxy global assessment of land degradation. Soil Use Manage 24, 223, 2008.

37. VOORTMAN R.L., SONNEVELD B.G., KEYZER M.A. African land ecology: Opportunities and constraints for agricultural development. Center for International Development Working Paper 37. Harvard University, Cambridge, Mass., U.S.A, 2000.

38. MALLICK J., RAHMAN A. Impact of Population Density on the Surface Temperature and Micro-Climate of Delhi. Current Science 1708, 102 (12), 25, 2012.

39. SINGH O., ARYA P., CHAUDHARY B. On rising temperature trends at Dehradun in Doon valley of Uttarakhand, India, J. Earth Syst. Sci. 122 (3), 613, 2013 http://dx.doi.org/ 10.1007/s12040-013-0304-0.
40. LI L., TAN Y., YING S., YU Z., LI Z., LAN H. Impact of land cover and population density on land surface temperature: case study in Wuhan, China. Journal of Applied Remote Sensing., 2014 https://oi.org/10.1117/1. jrs.8.084993

41. QIAO Z., TIAN G., XIAO L. Diurnal and seasonal impacts of urbanization on the urban thermal environment: a case study of Beijing using MODIS data. ISPRS J Photogramm Remote Sens 85, 93, 2013.

42. GHOBADI Y., PRADHAN B., SHAFRI H.Z.M., KABIRI K. Assessment of spatial relationship between land surface temperature and landuse/cover retrieval from multi-temporal remote sensing data in South Karkheh Sub-basin, Iran. Arab. J. Geosci., 8, 525, 2015.

43. FATEMI M., NARANGIFARD M. Monitoring LULC changes and its impact on the LST and NDVI in District 1 of Shiraz City. Arab. J. Geosci. 2019.

44. LIANG B.P., LI Y., CHEN K.Z. A Research on Land Features and Correlation between NDVI and Land Surface Temperature in Guilin City. Remote Sensing Technology \& Application 27, 429, 2012.

45. DENG Y., WANG S., BAI X., TIAN Y., WU L., XIAO J., CHEN F., QIAN Q. Relationship among land surface temperature and LUCC, NDVI in typical karst area. Sci. Rep. 2018

46. MALLICK J. Land Characterization Analysis of Surface Temperature of Semi-Arid Mountainous City Abha, Saudi Arabia Using Remote Sensing and GIS. J. Geogr. Inf. Syst. 2014.

47. BINDAJAM A.A., MALLICK J., ALQADHI S., SINGH C.K., HANG H.T. Impacts of Vegetation and Topography on Land Surface Temperature Variability over the SemiArid Mountain Cities of Saudi Arabia. Atmosphere, 11, 762, 2020.

48. ASSIRI M.E. Assessing MODIS Land Surface Temperature (LST) Over Jeddah. Polish Journal of Environmental Studies., 26 (4), 1461, 2017. doi:10.15244/ pjoes $/ 68960$.

49. TIAN Y., BAI X., WANG S., QIN L., LI Y. Spatialtemporal changes of vegetation cover in Guizhou Province, Southern China. Chinese Geogr. Sci. 2017.

50. QIN L., BAI X., WANG S., ZHOU D., LI Y., PENG T., TIAN Y., LUO G. Major problems and solutions on surface water resource utilisation in karst mountainous areas. Agric. Water Manag. 2015.

51. MALLICK J., AL-WADI H., RAHMAN A., AHMED M. Landscape dynamic characteristics using satellite data for a mountainous watershed of Abha, Kingdom of Saudi Arabia. Environ. Earth Sci. 2014.

52. ROTJANAKUSOL T., LAOSUWAN T. Model of Relationships between Land Surface Temperature and Urban Built-Up Areas in Mueang Buriram District, Thailand. Polish Journal of Environmental Studies., 29 (5), 3783, 2020. doi:10.15244/pjoes/116384.

53. CHAPMAN S., WATSON J.E.M., SALAZAR A., THATCHER M., MCALPINE C.A. The impact of urbanization and climate change on urban temperatures: a systematic review. Landsc. Ecol. 2017.

54. LI W., CAO Q., LANG K., WU J. Linking potential heat source and sink to urban heat island: Heterogeneous effects of landscape pattern on land surface temperature. Sci. Total Environ., 586, 457, 2017.

55. IPCC. Part A: Global and Sectoral Aspects. (Contribution of Working Group II to the Fifth Assessment Report of the Intergovernmental Panel on Climate Change). In Climate 
Change 2014-Impacts, Adaptation and Vulnerability; IPCC: Geneva, Switzerland, 2014.

56. COUTTS A.M., HARRIS R.J., PHAN T., LIVESLEY S.J., WILLIAMS N.S.G., TAPPER N.J. Thermal infrared remote sensing of urban heat: Hotspots, vegetation, and an assessment of techniques for use in urban planning. Remote Sens. Environ. 2016.
57. ZHAO Q., WENTZ E.A., MURRAY A.T. Tree shade coverage optimization in an urban residential environment. Building and Environment. 115, 269, 2017. doi: 10.1016/j. buildenv.2017.01.036. 